securities, as you wish to preserve it. Maintain the constitution which we labored so painfully to establish, and which has been to you such a source of inestimable blessings. Preserve the Union of the States, cemented as it was by our prayers, our tears, and our blood. Be true to God, to your country and to your duty. So shall the whole Eastern world follow the morning sun to contemplate you as a nation; so shall all generations honor you as they honor us; and so shall that Almighty power which so graciously protected us and which now protects you, shower its everlasting blessings upon you and your posterity.",

\section{HYGIENE AND PHYSIOLOGY OF THE SEXUAI SPHERE, AND THE PHYSICIAN'S RELATION TO THE LAITY AS REGARDS THIS SUBJECT.}

BY SYDNEY BARRINGTON ELLIOTT, M.D., of LOCISYILLE, $\mathrm{KY}$.

This is a subject of universal interest, and vital importance to all mankind, whether it be considered from a physical, moral, social, or medical standpoint. It lies at the foundation of all human improvement, and enduring progress. The function of reproduction as examined into by the most scientific physiologists, and moralists, is considered to be the most influential of the human economy. Nowhere does knowledge mean so much, because here it materially influences morals, public health, population, disease, mortality; besides personal reputation, property, legitimacy, and even life itself. Yet in spite of this, it is a subject which is not taught in medical colleges, is ignored in text books on physiology-even ministers are ignorant on it; and worse than all, physicians are doing little to lift the veil of mock-modesty and hypocracy which keeps the masses in ignorance and vice. Is it not an outrage on the people that they should be allowed to live, propagate and bring up children in entire ignorance and darkness as to this the most important of all subjects; while every trade, profession, and occupation, and every other branch of physiology are taught, and have light thrown upon them to all? True physiology teaches that, in the proper exercise of any natural faculty, or propensity in man, there is nothing that is impure, low, sensualizing, or in any way degrading. Then is it not high time that true hygiene and physiology of the sexual organs should be taught to all? For the amount of misery, disease and crime, resulting from abuse of these organs, through ignorance, is appalling; and few would give credit to its alarming extent. In ancient times the physical side of man dominated the intellectual; in more modern times the intellectual ruled the physical; and now, the time has come for the moral faculties to govern the intellectual and all others. In early life, even while a child is yet in the cradle, bad habits are formed of touching and playing with the sexual organs, as a result of improper diet, and external physical irritation. Physiology explains this in that the sexual organs are lined with similar mucous membrane to that of the mouth, stomach, bowels and other organs; and when part of this membrane becomes irritated any part of the body covered or lined with this membrane, may become deranged. Tea, coffee, meats, spices and confectionery are the principal causes of irritation of these organs at this early age. If children are fed to develop permanent congestion and constant irritation of the pelvic organs, then precocious and entirely morbid amativeness must result. Such children become an easy prey, and are early led astray by the bad influence of morally corrupt associates, to which every child is more or less exposed. None will deny that it is best that the young, especially the males, should, to a certain extent, be informed on these things; but is it right, is it wise, is it safe that they should be initiated into this subject by those of low morals? Is it not the parents' duty to give the children a rightful knowledge of this subject at the proper time, and is it not the physician's duty. to enlighten and advise the parents on such a vital matter? If children are liable to contract bad habits in infancy, they are ten-fold more so at the age of puberty, because of the sudden and rapid development of the sexual organs, with consequent great amorous impulse at this time; in fact, touching and manipulating are almost instinctively developed. As a result of such artificial excitation, a child is in the most perilous danger of contracting the baneful habit of masturbation, which may mean the ruination of the victim morally, mentally and physically. Is not the weight of responsibility tremendous on those who have the guardianship of children during this critical period? For a child without careful, watchful guidance at this time, is in a worse state than a ship without a pilot in a storm, among rocks and hidden shoals. The inseparable relation of the moral and physical life is seen at this age; and it is the greatest fallacy to endeavor to separate mind and body in educational arrangements. Children must be taught to eat; drink, dress, and exercise hygienically; and be given proper moral instruction. This would greatly tend to make them healthy in body and mind, and fit for the duties and hardships of after life; and they in turn would have well-born off-spring.

In marriage there are no means adopted to prevent the diseased and infirm from entering the matrimonial state and begetting children like themselves. People mate with everyone and anyone, regardless of health, age, temperament, and the means and abiljty to support and educate a family. It cannot be denied that premature, late and ill-assorted marriages, as well as those among the diseased and infirm are highly injurious to the procreation of vigorous, healthy offspring, and to public morality; nor can it be denied that this evil exists to a most alarming extent. The disease, suffering and vice resulting from such marriages, are not confined alone to one family, but are handed down from generation to generation. Is it not essential, then, for the prevention of such catastrophes that the public should be enlightened on this subject? If the unsound and the vicious, as well as those without the means and ability to support a family will marry or have illegal intèrcourse, is it necessary, is it right, is it just that such should beget children when there are hygienic means to prevent conception?

A large per cent. of the uterine diseases and disorders result from too frequent and improper sexual intercourse; and from the same cause an equally large per cent. of men suffer from lack of vim, tonacity and vigor. Because of ignorance should women suffer from deplorable disease and misery, and should men fail in life and fail to attain to the highest their 
ability is capable of on account of having their energy and life force sapped out, through this too frequent intercourse? If men and women were enlightened on this subject, they would not go to excesses, and so injure themselves and each other, they would lead healthful lives, and not constantly goad the sexual passion into abnormal intensity, by means of gross and stimulating food.

While eminent physiologists and scientists concede the wonderful and almost unlimited extent of prenatal influence, the masses of the people are entirely ignorant of it. If people, who are at all healthy, well mated and well disposed, by taking advantage of prenatal influence, can have children, who will be free from all taint of inherited disease and vice, who will only have the seeds of virtue sown, and still further, can have children who will naturally attain to the very highest in whatever calling they are adapted for; then, is it not of the most vital importance that they should be enlightened on this subject? If this were known to all, the parents, who were fit to have children, would have only those who were well born, free from all contamination, capable of almost unlimited attainment; and if those not fit to have children, whether from disease, vice or imperfection, were informed as to how to prevent conception in a proper, hygienic way, then all classes of unfortunates would soon be no more.

At the present time there is just as much disease and suffering, and consequently crime, as ever. All good influences, whether physical, intellectual or moral are entirely inadequate. For one sufferer relieved, one reform made there are countless downfalls. The effect, not the cause, is being dealt with, and while this continues, no material good can result. Every second of the hour, a human soul is born into the world and of these, the majority go to take the ranks of the unfortunates, whether of the imperfect, the vicious, or the diseased. To remedy this, is not in every case to prevent these unfortunates from coming into the world, but to take such measures that they will be born healthy in body and mind. To accomplish this end, physicians are largely responsible; for it is in their hands that the welfare of the public, to a large extent, lies. They are the fountain source of knowledge as to health; and on them must depend, not only the cure, but the prevention of disease. For if it is a high and noble thing to cure disease,it is far more so to prevent it; and as all true physicians have only the permanent welfare of the people at heart they will leave no stone unturned to accomplish this end.

THE FATTY AND FIBROID DEGENERATIONS. BY EPHRAIN CUTTER, M.D., LI.D., AXD JOHN ASHBURTON CUTTER, M.D., OF NEW YORK.

ALCOHOL A CAUSE OF FATTY DEGENERATION.

The use of alcohol is so common that this subject would not be well treated were not an allusion made to the effect of alcohol in producing fatty degeneration. Systemic writers so put it, and there is good reason, for alcohol is $\mathrm{C}_{2} \mathrm{H}_{6} \mathrm{O}$ while fat is $\mathrm{CHO}$ in varied proportion. Both are hydrocarbons and convertible with very little change in proportion. Alcohol acutely produces what fatty and fibrous degeneration produce chronically.
Drunkenness may well sometimes be called acute locomotor ataxy, and insanity, acute softening of the brain, acute paralysis and want of coördination. The mental vagaries of a drunken man are like those of people paralyzed more or less, so much so that people paralyzed from fatty brain degeneration have been mistaken and locked up as drunkards.

Some years ago a Mayor of a New Hampshire city was found in the Boston and Lowell railroad station in Boston helpless and unable to explain himself. The station officials turned him over to the police, and they locked him up as a drunkard. His family hunted him up and on being told that he never used liquor, the police authorities found that he suffered from paralysis caused by a cerebral hemorrhage.

A late writer says "a too free use of oils and fatty foods and of alcoholic beverages, produces red, blotched face and swollen carbunculated nose, oily surface, erythematous swelling, and redness of the skin generally."

But not only in symptoms does alcoholism resemble fatty nerve degeneration, but the autopsies have shown fatty degeneration of liver and other organs, it may be by causing the circulation to be languid or partially impeded, as well as by kinship in chemical elements.

This effect of alcohol should induce great care in its use in diseases of fatty degeneration, as the true way to treat such cases, is to avoid the use in food and drinks of any substance which can be converted into fat, wax, lard or soap, which is a prominent feature of late food expositions. Evidence against desired.

FATTY DEGENERATION OF THE EYES.

In view of Dr. B. W. Richardson and S. Weir Mitchell's animal experiments, showing the sudden production of cataract in the eyes from the subcutaneous injection of sugar, and in view of the prevalence of eye diseases which come from degradation of ocular tissues into the various forms of fatty degeneration, in the cornea, arcus senilis; in the crystalline lens, cataract, in the aqueous humour, in the retina, in the optic nerve and flatness of the eyeball from want of proper tensile and textile strength, this subject becomes of absorbing interest to all concerned.

Food is here an agent of tremendous power for good or ill.

Once a clergyman 76 years of age, said to me that he had been forbidden by his oculists to preach or use his eyes, on account of amaurosis, which meant blindness. "Now," said he, "can you suggest anything for me?" I said I could as I deemed amaurosis one phase of fatty degeneration. He went on to the diet I told him of, which excluded carbo-hydrates -the results were that until the age of 84 , he preached to the spirits in prison (so he said the last time I saw him, a few weeks before his death), in Concord, Mass., State prison, and his sight grew no worse, in place of the complete blindness predicted and which would have happened probably had he lived on ordinary diet. Fat is all right outside the eyeball as a cushion, but when it replaces the substance of ocular tissues it is a mischief breeder. The writer is convinced that these things should be better understood by the Blind Asylum authorities, and those who bring up children, and that they should regulate their diet, so as not to have an excess of carbo-hydrates and a loss of normal mineral salts. 